\title{
Cervical artificial disc replacement (C-ADR): global perspectives on use and trends
}

\author{
Authors John Rhee ${ }^{1}$, Ellen M VanAlstyne ${ }^{2}$, Andrea C Skelly ${ }^{2}$ \\ Institutions ${ }^{1}$ Orthopaedic Surgery, Emory Spine Center, Emory University School of Medicine, Atlanta, GA, \\ USA \\ ${ }^{2}$ Spectrum Research Inc, Tacoma, WA, USA
}

\section{ABSTRACT}

Study design: Cross-sectional survey.

Objectives: To obtain information from the global community regarding cervical artificial disc replacement (C-ADR) use and trends before and after US Food and Drug Administration (FDA) approval of devices in 2007 and summarize available information on utilization and government approval for devices.

Methods: Data on utilization and approval were sought from PubMed, Google, FDA, and manufacturers' websites. The 6195 members of AOSpine International were invited to participate in a survey to assess global C-ADR use and trends.

Results: Publically available data on utilization, trends, and approval outside of the US and Europe is limited. No studies of utilization were found. Of 1479 professionals responding to the survey, 50\% had C-ADR specific training and reported ever performing C-ADR. Most respondents believed that C-ADR was safe and effective, but approximately one quarter responded that they did not know. Of those who had done C-ADR, $49 \%$ reported performing $\geq 1$ before December compared with $92 \%$ after January 2008 and 51.3\% indicated that all their C-ADRs were placed in a single level; $27 \%$ reported $\geq 1$ failures that required revision. The majority foresee that C-ADR use will increase in the next 5 years. Most respondents believed that the best indication is radiculopathy from soft-disc pathology rather than myelopathy or disorders arising from spondylotic (hard-disc) pathology.

Conclusion: More C-ADR has been performed after January 2008. Most respondents expect the number to increase. There may be differences in failure rates when performed inside or outside of a sponsored research trial. 


\section{STUDY RATIONALE AND CONTEXT}

Cervical artificial disc replacement (C-ADR) has been introduced as an alternative to anterior cervical discectomy and fusion for the treatment of degenerative conditions of the cervical spine. The major potential benefit over anterior cervical discectomy and fusion (ACDF) is in preservation of segmental motion that may in turn provide benefits in clinical outcomes, such as pain and adjacent segment disease. Short-term (2 years) outcomes in randomized, controlled, prospective trials demonstrate that CDRs might perform comparably to ACDF. However, many questions remain regarding longer-term outcomes, such as durability, modes of failure, rates of adjacent segment disease, and long-term pain relief. In addition, outcomes with respect to C-ADR have generally been reported in the setting of company-sponsored studies for the purposes of gaining the US Food and Drug Administration (FDA) approval. Little is known about the utilization and outcomes of C-ADR when performed outside of this setting. Thus, practicing surgeons currently must make decisions regarding the use of C-ADR based on perceptions and incomplete information.

\section{OBJECTIVES}

To obtain information from the AOSpine International (AOSI) community regarding C-ADR use and trends before and after FDA approval of devices in 2007 and summarize available information on utilization and government approval for devices.

The purpose of the survey was to obtain information from the AOSI membership regarding C-ADR use and trends. The specific aims were to:

- Describe spine surgeons' perspectives on the use, efficacy, and safety of C-ADR on a global level

- Estimate C-ADR use among AOSI members

- Describe variations in C-ADR use by region and other factors

\section{MATERIALS AND METHODS}

Study design: Literature search and cross-sectional survey.

Sampling: Literature and related searches: A PubMed search for studies of C-ADR utilization was conducted from 1991 through November 2011. Google, FDA, and manufacturers' websites were searched. Manufacturers of devices were offered the opportunity to respond to a survey about utilization, trends, and approval outside of North American and Europe but all declined to provide information.

Survey: The survey was designed to meet the above objectives primarily using questions requiring categorical responses to decrease respondent burden. Surgeon input on survey content and design was obtained.

All AOSI members $(\mathrm{N}=6195)$ were invited via email to participate in an online survey regarding C-ADR. The survey was available electronically on Survey Monkey ${ }^{\circledR}$ for 18 days and two reminder emails were sent 10 days apart. As incentive to participate, those completing the survey were entered into a drawing for an iPad $2^{\circledR}$.

Demographic data from the AOSI membership database were merged with respondent data for analysis.

Primary outcomes of interest included training in and use of C-ADR, patterns of use before and after FDA approval of devices in 2007 and use in specific patient conditions.

Descriptive statistics were used to summarize the data.

Details about methods and the survey instrument used can be found in the Web Appendix at www.aospine.org/ ebsj

Fig 1 Survey sampling and responses.

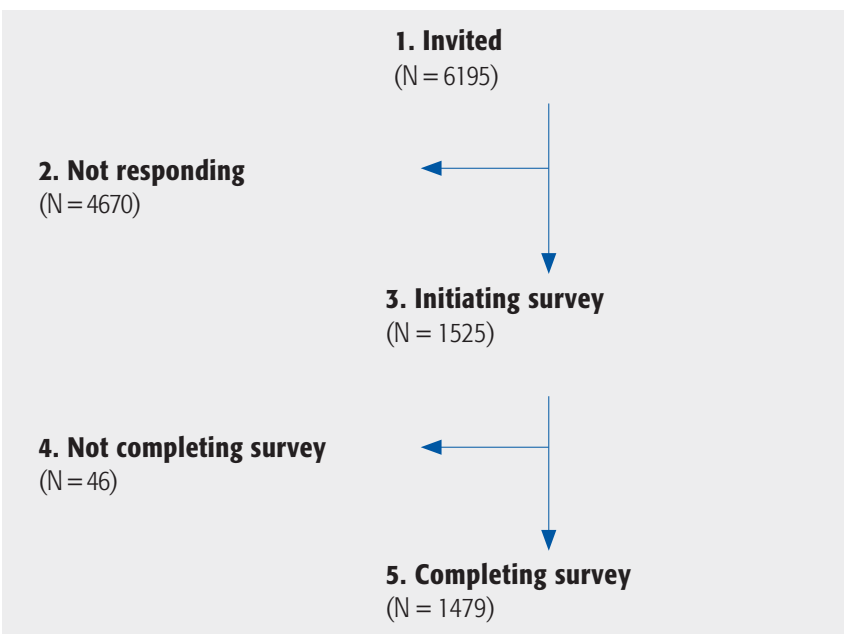




\section{RESULTS}

\section{Literature and other sources}

- No formal utilization studies of C-ADR for treatment of degenerative disc disease were found in PubMed. The number of citations related to cervical artificial disc replacement in PubMed has steadily increased since 2001, particularly since the FDA approval of two devices in 2007. (See web appendix).

- Publically available information on utilization and trends is limited. Data from the FDA and manufacturers' websites indicates that fewer discs have received FDA approval than have received the European CE mark. Government/regulatory approval status for countries outside of North America and Europe was not readily available. (See Web appendix).

- The PubMed searched yielded one report of a survey of surgeons [1] on practices and attitudes regarding disc replacement (see Web appendix for strategy and study selection diagram):

- Surveys were returned from 113 of 133 surgeons present at the 2007 "Contemporary Update on Disorders of the Spine" meeting in Whistler, BC, Canada.

- Of those, 30\% had performed C-ADR at the time of survey, of which $91 \%$ had been or were involved in an FDA trial evaluating these devices. The mean number of surgeries done was $15.5 \pm 8.5$ cases per surgeon, but $46 \%$ of respondents had done $<10$ surgeries at the time of survey. Of those who had not done C-ADR surgery at time of survey, $81 \%$ said they were more likely to do so than a year prior. Of all surgeons, 51\% predicted C-ADR would eventually be the gold standard treatment, replacing cervical fusion, for symptomatic cervical spondylosis and/or herniated nucleus pulposus.

- Benefits of C-ADR compared with fusion were cited for range of motion by $66 \%$; axial pain relief, $38 \%$; radicular symptom relief, $35 \%$; and reduction adjacent segment disease, $52 \%$ of respondents.

- Reasons given for not performing C-ADR included no appropriate candidates for surgery $(21 \%)$, questioning short-term outcomes $(23 \%)$, questioning long-term outcomes (56\%), no experience with the technique $(35 \%)$, concerns about revisions $(43 \%)$, and perceived difficulty with precertification (to secure financial approval from insurance companies) $(53 \%)$ of respondents.

\section{Survey results}

Survey invitations were sent via email to 6195 AOSI members, with 1525 individuals initiating the survey (24.6\%), representing 90 countries. Of the 1525 individuals who initiated the survey, 1479 (97\%) answered the last two questions and were considered to have completed the survey (Fig 1).

- Demographics of respondents completing survey (Table 1): The majority was male (96.6\%). More than 50\% had fellowship training in orthopaedic surgery and practiced in academic settings (ie, were university affiliated). Most had been in practice for 10 years or less. The largest percentage of respondents was from the European region (32.5\%).

Table 1 Characteristics of survey respondents.

\begin{tabular}{|c|c|c|}
\hline & & $\begin{array}{l}\text { Completed survey } \\
(\mathrm{N}=1479) \text {, No. }(\%)\end{array}$ \\
\hline \multirow[t]{2}{*}{ Gender } & Male & 1425 (96.7) \\
\hline & Female & $49(3.3)$ \\
\hline \multirow[t]{4}{*}{ Specialty* } & Neurosurgeon & $418(26.3)$ \\
\hline & Orthopaedic surgeon & $509(34.4)$ \\
\hline & Spine surgeon & $430(29.1)$ \\
\hline & Other $^{\dagger}$ & $122(10.3)$ \\
\hline \multirow[t]{3}{*}{ Fellowship } & Yes - orthopaedic & $829(56.1)$ \\
\hline & Yes-neurosurgery & $370(25.0)$ \\
\hline & No & $280(18.9)$ \\
\hline \multirow[t]{6}{*}{ Years in practice } & $<5$ & $469(31.7)$ \\
\hline & $5-10$ & $351(23.7)$ \\
\hline & $11-15$ & $214(14.5)$ \\
\hline & $16-20$ & $162(11.0)$ \\
\hline & $>20$ & $162(11.0)$ \\
\hline & Never/not currently ${ }^{\ddagger}$ & $121(8.2)$ \\
\hline \multirow[t]{3}{*}{ Setting } & $\begin{array}{l}\text { Academic (university } \\
\text { affiliated) }\end{array}$ & $864(58.4)$ \\
\hline & Nonacademic & $518(35.0)$ \\
\hline & Other & $97(6.6)$ \\
\hline \multirow[t]{6}{*}{ AOSI Region } & Africa & $25(1.7)$ \\
\hline & Asia-Pacific & $360(24.3)$ \\
\hline & Europe & $481(32.5)$ \\
\hline & Latin America & $232(15.7)$ \\
\hline & Middle East & $109(7.4)$ \\
\hline & North America & $272(18.4)$ \\
\hline
\end{tabular}

* Based on AOSpine International membership classifications.

† Includes neurologists, residents, physical therapists, nurses, commercial/business members, research/clinical investigations, and radiology.

₹ I have never been/am not currently a practicing spine surgeon. 
- C-ADR training and beliefs (Fig 2): Half of the respondents reported having had C-ADR specific training and reported ever performing this procedure. While most respondents believed that C-ADR was safe and efficacious (including over the long-term), approximate one quarter responded that they did not know. Most foresee that C-ADR use will increase in the next 5 years.

Table 2 Summary of responses from those who have never performed cervical artificial disc replacement (C-ADR).

\begin{tabular}{|c|c|}
\hline & $\begin{array}{l}\text { Total }(\mathrm{N}=633) \text {, } \\
\text { No. }(\%)\end{array}$ \\
\hline \multicolumn{2}{|l|}{ Primary reason for not performing } \\
\hline Have not had training in C-ADR & $173(27.3)$ \\
\hline $\begin{array}{l}\text { Don't know/don't believe they are } \\
\text { efficacious long term }\end{array}$ & $117(18.5)$ \\
\hline $\begin{array}{l}\text { Practice does not include candidates for } \\
\text { C-ADR }\end{array}$ & $75(11.9)$ \\
\hline Other & $56(8.9)$ \\
\hline I am not a spine surgeon & $54(8.5)$ \\
\hline Devices not readily available in my country & $46(7.3)$ \\
\hline $\begin{array}{l}\text { Don't know/don't believe they are safe long } \\
\text { term }\end{array}$ & $43(6.8)$ \\
\hline Cannot be reimbursed for C-ADR & $33(5.2)$ \\
\hline Devices not approved in my country & $36(5.7)$ \\
\hline $\begin{array}{l}\text { Foresee that I will perform C-ADR in } \\
\text { next } 5 \text { years }\end{array}$ & $406(64.1)$ \\
\hline
\end{tabular}

- Those who do not currently perform C-ADR (Table 2): Not having training was the most common reason given for not performing C-ADR (27.3\%) followed by not knowing or believing in C-ADR long-term efficacy (18.5\%).

- Among those who reported ever performing C-ADR (Fig 3):

- Only 49\% reported performing one or more before December compared with 92\% after January 2008.

- $91.8 \%$ and $81.0 \%$ of respondents reported using C-ADR for radiculopathy and soft-disc pathology, respectively. The majority reported that they had not placed discs for myelopathy $(66.1 \%)$, hard disc pathology $(53.5 \%)$, or adjacent to a prior fusion $(58.2 \%)$.

- $27 \%$ reported that they had one or more C-ADR failures that required a revision.

- $51.3 \%$ indicated that all their C-ADRs were placed in a single level.

Table 3 Level of agreement regarding appropriateness of cervical artificial disc replacement (C-ADR) for various clinical situations.

\begin{tabular}{llllll}
\hline & $\begin{array}{l}\text { Strongly } \\
\text { agree, No. } \\
(\%)\end{array}$ & $\begin{array}{l}\text { Agree, No. } \\
(\%)\end{array}$ & $\begin{array}{l}\text { Unsure, No. } \\
(\%)\end{array}$ & $\begin{array}{l}\text { Disagree, } \\
\text { No. }(\%)\end{array}$ & $\begin{array}{l}\text { Strongly } \\
\text { disagree, } \\
\text { No. }(\%)\end{array}$ \\
\hline Soft-disc pathology & $354(48.2)$ & $279(38.0)$ & $77(10.5)$ & $17(2.3)$ & $8(1.1)$ \\
\hline Radiculopathy & $297(40.4)$ & $367(49.9)$ & $50(6.8)$ & $16(2.0)$ & $6(0.8)$ \\
\hline $\begin{array}{l}\text { Segments adjacent to } \\
\text { prior fusion }\end{array}$ & $119(16.2)$ & $307(41.8)$ & $220(29.9)$ & $64(8.7)$ & $25(3.4)$ \\
\hline $\begin{array}{l}\text { Spondylotic hard-disc } \\
\text { pathology }\end{array}$ & $55(7.5)$ & $205(27.9)$ & $221(30.1)$ & $164(22.3)$ & $90(12.2)$ \\
\hline \begin{tabular}{l} 
Myelopathy \\
\hline
\end{tabular} & $40(5.4)$ & $172(23.4)$ & $207(28.2)$ & $187(25.4)$ & $129(17.6)$ \\
\hline
\end{tabular}

Fig 2 Respondent C-ADR training, beliefs about efficacy, safety, and future trends.

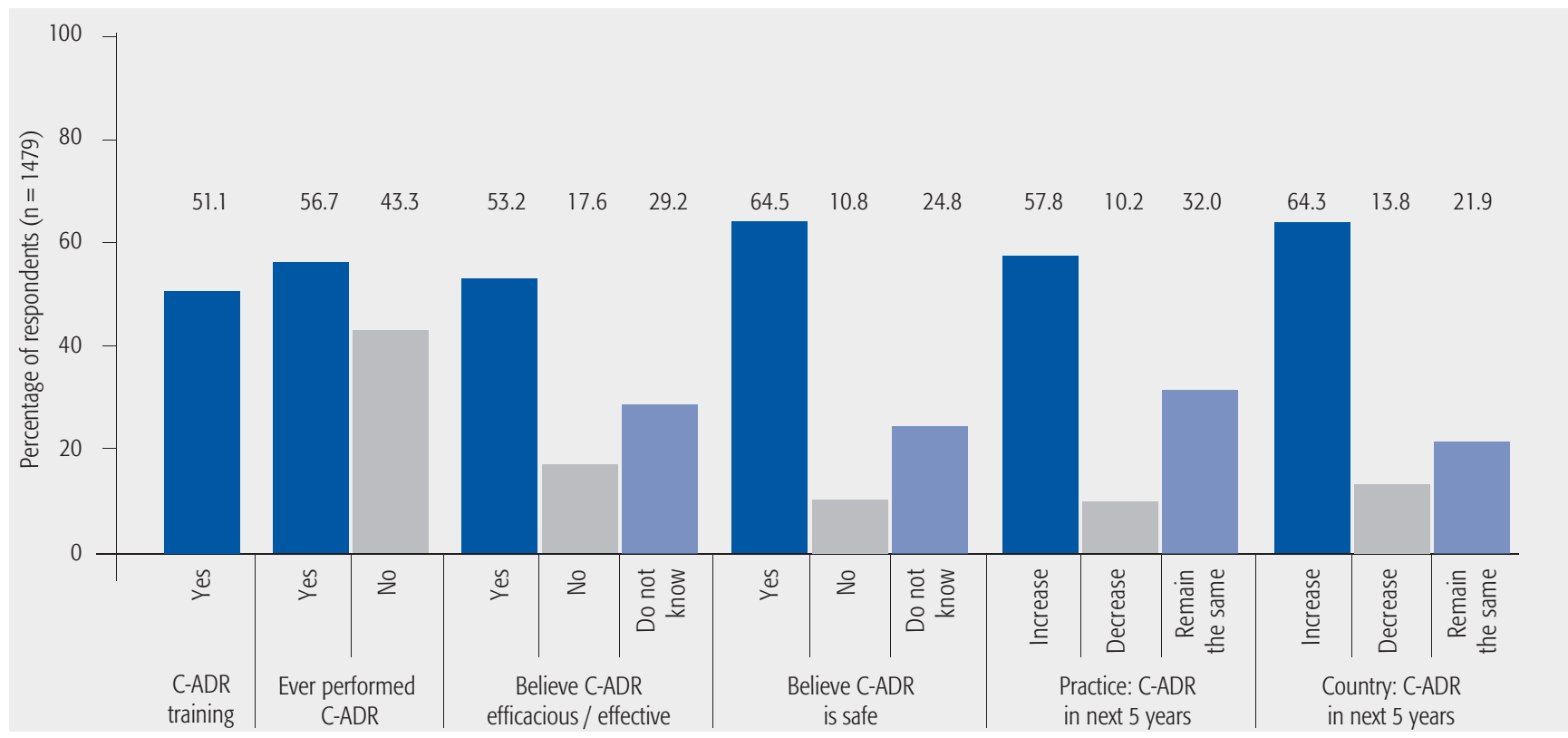


- C-ADR by AOSI region (Fig 4):

- Within each region, higher percentages of respondents indicated performing C-ADR after January 2008 than before December 2007.

- Of those who reported ever performing C-ADR, $38.3 \%$ were from Europe, $21.6 \%$ Asia-Pacific, $19.2 \%$ North America, 5.3\% Middle East, and 1.6\% from Africa. (The total number of respondents from Africa was 25, and 13 of them indicated that they had performed C-ADR).

- Perspective on appropriateness of use among those who have performed C-ADR (Table 3):

- Most respondents strongly agreed or agreed that C-ADR was appropriate in patients presenting with radiculopathy $(90 \%)$ or soft-disc pathology $(86 \%)$.

- $58 \%$ strongly agreed or agreed that C-ADR was appropriate in segments adjacent to a prior fusion.

- $58 \%, 35.4 \%$, and $28.8 \%$ strongly agreed or agreed regarding the appropriateness of C-ADR adjacent to a prior fused segment, for spondylotic hard-disc pathology and myelopathy, respectively. Approximately $30 \%$ were unsure regarding C-ADR appropriateness in patients with these indications.

- Devices used by respondents: Among those who reported ever performing C-ADR, the most commonly used devices were ProDisc ${ }^{\odot} \mathrm{C}$, PRESTIGE ${ }^{\odot}$ LP or ST and the Bryan $^{\oplus}$ disc. Respondents may have used more than one device.

Fig 3 Summary of C-ADR placement with respect to timing of FDA approval (2007), clinical condition, and C-ADR failures requiring revision.

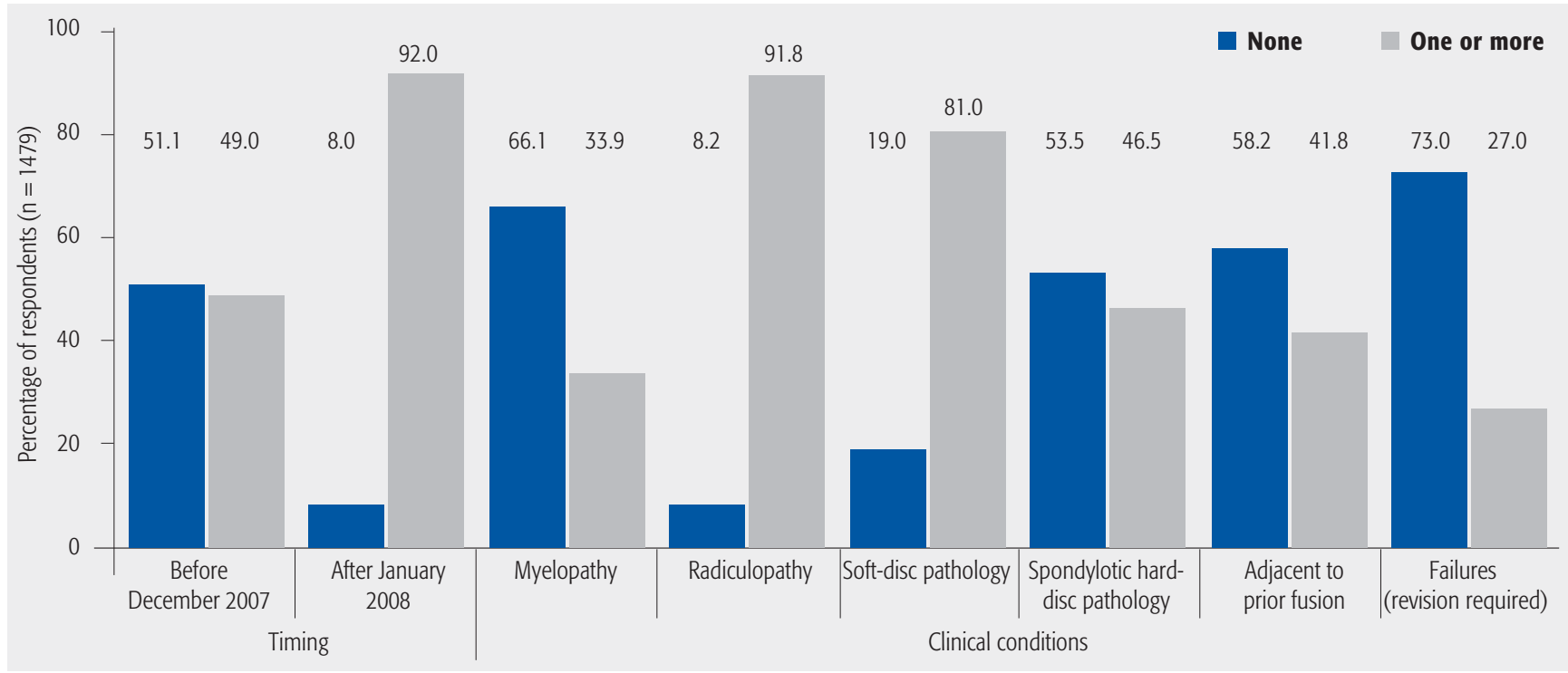

Fig 4 Summary of C-ADR utilization within regions.

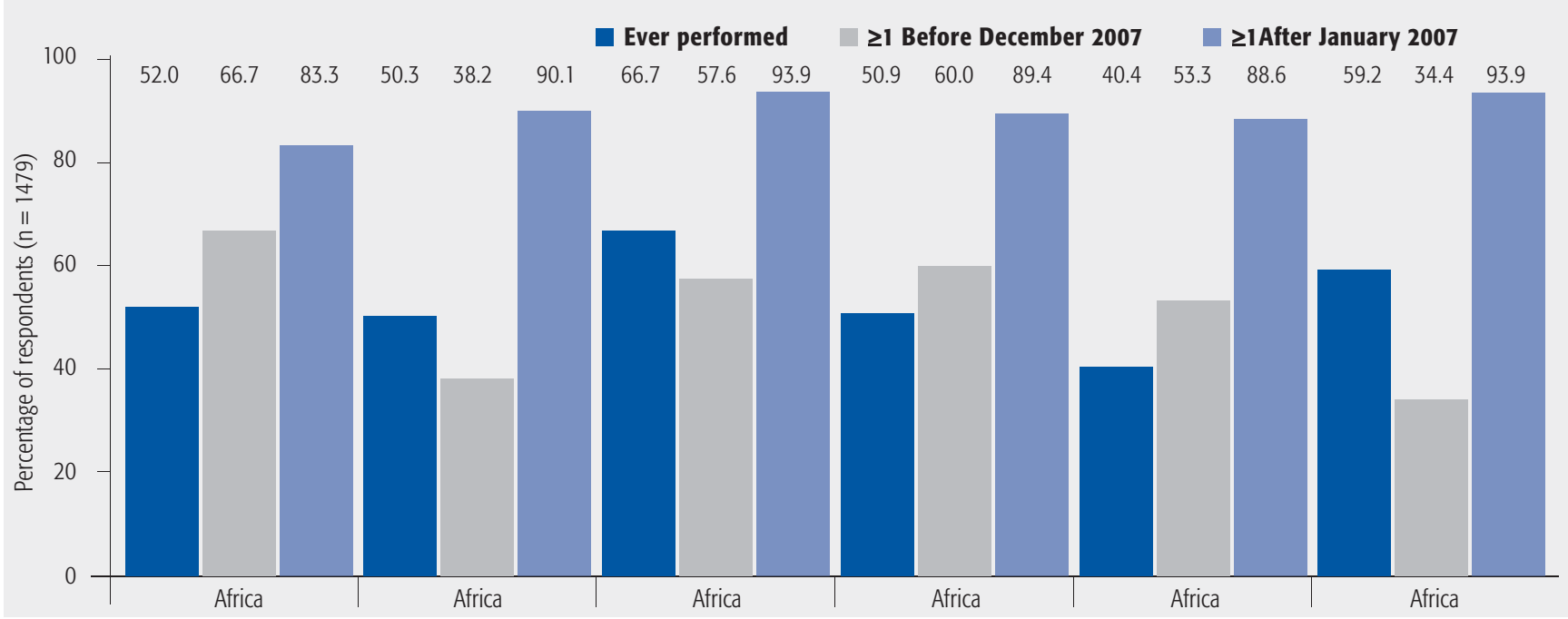




\section{DISCUSSION}

Despite overall favorable outcomes currently reported in the C-ADR literature, respondents were appropriately cautious when describing their indications for use.

- Approximately $25 \%-30 \%$ are not convinced that CADR is safe and effective.

- Only $28.8 \%$ agree/strongly agree that myelopathy is an appropriate indication for C-ADR.

- Only 35.4\% agree/strongly agree that spondylotic radiculopathy is an appropriate indication for C-ADR.

- $58 \%$ agree/strongly agree that adjacent segment disease is an appropriate indication for C-ADR.

Thus it appears that the respondents' ideal indication for CTDR is in the patient with radiculopathy from soft-disc herniation. Despite this, $57.8 \%$ believe their personal usage will increase over the next 5 years.

Among those having performed C-ADR, 27\% of respondents indicated having one or more C-ADR failures requiring revision. There is no denominator information available in the survey (only the percentage of respondents reporting revision), so it is not clear how revision rates in the global community compare with those quoted in the literature. However, this number suggests a possibly higher rate of failure when C-ADR is performed outside of an IDE trial.

- In the Prodisc-c trial [2], for example, 98\% of TDRs did not require revision, removal, reoperation, or supplemental fixation at 2-year follow-up. Similar device success rates have been reported for the Bryan [3] and Prestige [4] trials at 2 years.

- The survey did not obtain detail regarding the causes and circumstances of the C-ADR failures reported. However, it may be that there are differences in the efficacy of CADR when performed outside of a clinical trial.

Further study on the long-term results associated with C-ADR, both inside and outside of the sponsored trials, needs to be performed before determining the superiority, equivalence, or inferiority of C-ADR versus ACDF.

Conclusions from the survey analysis are limited by the following:

- This a convenience sample of AOSI members and a scientifically valid response rate was not achieved.

- It is possible that those who chose to respond to the survey are more likely to be performing C-ADR or interested in doing so compared with nonrespondents. Training in C-ADR use is likely to have been industry sponsored for the $51 \%$ who reported training. These factors potentially could bias the results in favor of C-ADR. Recall bias is also possible.

- There were a limited number of respondents from the African region $(n=25)$ compared with other regions.

\section{CONCLUSIONS}

- The majority of C-ADRs have been performed after January 2008, and most respondents expect the number of C-ADRs to increase in their own practices as well as in their home countries over the next 5 years.

- Most respondents believe that the best indication for CADR is radiculopathy from soft-disc pathology, rather than myelopathy or disorders arising from spondylotic (hard-disc) pathology.

- There may be differences in C-ADR failure rates when performed inside or outside of a sponsored research trial.

\section{ACKNOWLEDGMENTS}

We thank Mike Fawcett for his assistance in putting the survey online, merging demographic data and other logistics; Devon Brewer, Dan Riew, and Dan Norvell for critique of survey design and content.

\section{REFERENCES}

1. Whang PG, Simpson AK, Rechtine G, et al (2009) Current trends in spinal arthroplasty: an assessment of surgeon practices and attitudes regarding cervical and lumbar disk replacement. J Spinal Disord Tech; 22(1):26-33.

2. Murrey D, Janssen $M$, Delamarter $R$, et al (2009) Results of the prospective, randomized, controlled multicenter Food and Drug Administration investigational device exemption study of the ProDisc-C total disc replacement versus anterior discectomy and fusion for the treatment of 1-level symptomatic cervical disc disease. Spine J; 9(4):275-286.

3. Heller JG, Sasso RC, Papadopoulos SM, et al (2009) Comparison of BRYAN cervical disc arthroplasty with anterior cervical decompression and fusion: clinical and radiographic results of a randomized, controlled, clinical trial. Spine (Phila Pa 1976); 34:101-107.

4. Mummaneni PV, Burkus JK, Haid RW, et al (2007) Clinical and radiographic analysis of cervical disc arthroplasty compared with allograft fusion: a randomized controlled clinical trial. J Neurosurg Spine; 6(3):198-209. 